\title{
Anemia due to Decreased Production
}

National Cancer Institute

\section{Source}

National Cancer Institute. Anemia due to Decreased Production. NCI Thesaurus. Code C131655.

Anemia that results from a decreased rate of erythropoiesis. 